\title{
PSYCHIATRIC MORBIDITY AMONG HIV VICTIMS
}

\author{
Viswanathan G. $A^{1}$, Ananda Krishna Kumar $S^{2}$, Sabhesan $S^{3}$
}

${ }^{1}$ Assistant Professor, Department of Psychiatry, Madurai Medical College, Madurai.

${ }^{2}$ Associate Professor, Department of Psychiatry, Madurai Medical College, Madurai.

${ }^{3}$ Retired Professor and HOD, Department of Psychiatry, Madurai Medical College, Madurai.

\section{ABSTRACT}

\section{BACKGROUND}

The natural course of HIV is a chronic, physically and psychologically disabling and stigmatising illness. The emotional distress and consequences of HIV are enormous which may modify the course, complications and outcome of illness. Psychiatric symptoms not only interfere with quality of life, but also interfere with functional capacity and treatment compliance. Early identification of emotional disturbances may help in effective management of both psychiatric aspects and physical consequences of HIV.

\section{MATERIALS AND METHODS}

The study aims to investigate the occurrence of emotional disturbances among patients with HIV disease, the sociodemographic and disease-related determinants of such emotional disturbances and the appropriate tool to screen such patients. A total of sixty patients were screened for non-psychotic psychiatric disturbances using General Health Questionnaire (GHQ), Hospital Anxiety Depression Scale (HADS) and Cornell Medical Index (CMI). The patients were clinically assessed by a senior psychiatrist.

\section{RESULTS}

Results indicated that psychiatric morbidity among HIV victims was very high, but majority of personal and clinical parameters were not predictive. Compared against the clinical assessment, all three instruments were found to evince varying reliability as screening devices.

\section{CONCLUSION}

HIV being a major public health problem, there is an urgent need to assess and to intervene psychological components of HIV. Mental Health professionals should be better trained in picking up cases early with instruments that are having higher inter-rater reliability with high sensitivity and specificity. The need to formulate an improved screening device is emphasised.

\section{KEYWORDS}

Psychological Morbidity in HIV, Personal and Disease-Related Correlates, Use of Screening Tools.

HOW TO CITE THIS ARTICLE: Viswanathan GA, Kumar AKS, Sabhesan S. Psychiatric morbidity among HIV victims. J. Evolution Med. Dent. Sci. 2017;6(33):2701-2704, DOI: 10.14260/Jemds/2017/583

\section{BACKGROUND}

All physical illnesses are attended by emotional consequences, more so if the illness is chronic, disabling and stigmatising. [1] HIV contributes to all types of stresses; biological, psychological and social. Biological symptoms include the physical debility, proneness to infections, disfiguring dermatological changes and a chronic course. Negative health-belief systems evoke in the sufferer a sense of guilt, alienation with stigmatisation and a fear of death and disability. Socially, even the immediate family distances itself because of fear of contagion and contempt over the manner of its acquisition. Social rejection is much more injurious than physical disabilities.

Psychiatric consequences of HIV result in poor quality of life and maladaptive health behaviour, resulting in noncompliance to treatment, chronic disability and personal and family disorganisation. Intensity of hostility and rejection by family members including the spouse is evident during

Financial or Other, Competing Interest: None.

Submission 19-03-2017, Peer Review 13-04-2017,

Acceptance 18-04-2017, Published 24-04-2017.

Corresponding Author:

Dr. Ananda Krishna Kumar $S$

Plot No.-14, Muthamil Nagar $3^{\text {rd }}$ Street,

P \& T Nagar, Madurai-625017.

E-mail:dr.anandakrish@gmail.com

DOI: $10.14260 /$ jemds $/ 2017 / 583$ clinical interviews. But, close family members often evince an ambivalent attitude, emotionally rejecting him on one hand but supporting him during needs. The patient himself presents with intense hostility against the society at large and against the family members in particular for the perceived rejection. One of the patients summed up that the best way to take revenge was to spread the illness to as many people as possible. Culturally accepted and yet, medically unacceptable health-belief systems further augment the schism between the sufferer and the society. Management of such emotional problems and maladaptive concepts often reversed these avoidable morbidities. Hence, the disturbed individual should be identified early. [2]

Assessment of psychological symptoms, distress and psychiatric disorders is important because when their presence is ignored, they increase physical morbidity, reduces self-esteem of the individual, interferes with their relationship with their family members and health professionals, reduces treatment seeking behaviour, lack of confidence in outcome of treatment and ultimately resulting in non-adherence to treatment. HIV patients suffering with anxiety, depression, adjustment problems, body image disturbances, fatigability, poor sleep and appetite make them prone to further immunosuppression, increase in physical morbidity and may lead to increase in medical morbidity, mortality, suicidal ruminations and ultimately patients die committing suicide. 
Identification of emotional problems among the physically ill can be done by clinical interviews, structured tests and self-administered questionnaires. Because of the difficulties in interpretation of psychiatric symptoms in the presence of physical illnesses and of the numerical vastness of the sufferers, the ideal method would be to use a standard screening devise of known reliability and validity which can be administered even by paramedical personnel. Initial screening could identify the emotionally disturbed patients in need of clinical evaluation and combined pharmacological and psychosocial interventions.[3] The major implications of the study are to understand the emotional disturbances in patients with HIV, their relationship with the personal and clinical variables. Further the study focuses on various screening tools to assess the psychological morbidity and to find out inter-correlation of these tools in their assessment so that an effective tool may be recommended for assessment with higher specificity and sensitivity in HIV patients.

The present study aims to find out the extent of psychopathology among HIV victims, their sociodemographic and clinical correlates and the usefulness or otherwise of three of the commonly used screening devices.

\section{MATERIALS AND METHODS}

The study was conducted in the ART Centre, Government Rajaji Hospital, Madurai from February 2007 to May 2007 after obtaining approval from Institutional Ethical Committee. Sixty patients who satisfied the following criteria were chosen among the out-patient population.

\section{Inclusion Criteria}

- Adult patients in the age group of 20 to 50 years were included.

- $\quad$ Patient should be willing to participate in the study.

\section{Exclusion Criteria}

- $\quad$ Patient suffering from any other illness such as diabetes or hypertension or any other complication such as tuberculosis, fungal infections or neurological manifestations.

- Very sick patients who were unable to participate the study.

\section{All the Sixty Patients were studied using the Following} Tools

1 Proforma to collect sociodemographic and illness related physical and psychological variables. Following a pilot study, proforma was further modified.
2 General Health Questionnaire (GHQ). The questionnaire has been extensively used as a screening device. The tool is easy to administer, acceptable to respondents and objective. The 28-item version was used.[4]

3 Hospital Anxiety Depression Scale (HADS). The scale has been devised to overcome the problem of contamination by illness-related physical symptoms in the selfassessment. The scale gives an independent measure of levels of anxiety and depression reliably.[5]

4 Cornell Medical Index (CMI). The M-R section has been used to screen the population for medically significant emotional disturbances. The questions are easy to administer. The tool has been used both in community surveys ${ }^{[6]}$ and among the patient populations. ${ }^{[7]}$

5 International Classification of Diseases- Research Diagnostic Criteria 10th Edition.[8]

Patients selected for the study were administered the screening tests in a single session and simultaneously, their sociodemographic details and disease related variables were collected using the proforma. Clinical diagnosis was made out independently on the same day by the senior author who was blind to the scores in the screening tests.

Raw scores were used in the analysis of the data. The diagnostic performance of the screening tests was tested against the interview-derived diagnosis. Sensitivity measured as 'True positive rate' and specificity measured as "True negative rate' were identified using specific methods. [9] Clinical association between variables, inter-correlations between variables and statistical inferences were identified using Chi-square test and Pearson's correlation.

\section{RESULTS}

A total of 60 patients were included in the study, including twenty five women. Their age ranged from 21 to 48 years with a mean of $34.5 \pm 7.2$ years. Twenty seven patients resided in Madurai city, 19 in the city suburbs and 14 in nearby rural domiciles. Three patients were Christians, three Muslims and the rest Hindus. Nineteen were illiterates; 21 had studied less than 5 years; 15 between 5 and 10 years and five more than 10 years. Twenty four among them were agricultural workers; 18 semi-skilled workers; seven were unemployed and the rest were variously employed. Three patients remained unmarried and the rest were married. Among the married, five were separated, two divorced and 15 had lost their spouses. Fourteen of them belonged to joint families, 11 to extended nuclear families and the rest were nuclear families.

\begin{tabular}{|c|c|c|c|c|c|c|}
\hline \multirow{2}{*}{ Instrument } & \multirow{2}{*}{ Cut-off Score } & \multicolumn{2}{|c|}{$\begin{array}{c}\text { Patients with } \\
\text { Significant Disturbances }\end{array}$} & \multirow{2}{*}{ Mean (SD) } & \multicolumn{2}{|c|}{ Range } \\
\hline & & No & $\%$ & & From & To \\
\hline GHQ & 7 & 60 & 100 & $55.05(52.4)$ & 16 & 75 \\
\hline HADS & & & & & & \\
\hline Anxiety & 7 & 18 & 30 & $7.08(4.3)$ & 0 & 18 \\
\hline Depression & 8 & 28 & 47 & 7.18 (5.8) & 0 & 20 \\
\hline CMI & 10 & 29 & 49 & $10.38(8.2)$ & 0 & 40 \\
\hline Clinical Interview & & 38 & 63 & & & \\
\hline
\end{tabular}

$\mathrm{N}=60$. 
Results of screening with the three devices and of the clinical diagnostic interviews were as given in Table 1 . The clinical diagnoses made on ICD - 10 criteria included Mild depression (F32.00) in 12 patients, moderate depression (F32.10) in 10 patients, severe depression (F32.2) in two patients, other depressive episodes (F32.8) in two patients, recurrent depressive disorder (F33.0) in three patients, episodic paroxysmal anxiety (F41.00) in one patient, adjustment disorder with prolonged depressive reaction (F43.21) in three patients, adjustment disorder with mixed anxiety and depression (F43.22) in two patients, and adjustment disorder with predominant disturbance of other emotions (F43.23) in three patients. Though clinical interview identified 38 patients as disturbed, GHQ identified all the sixty as scoring above the cut-off score. Eighteen patients in HADS Anxiety, 28 in HADS Depression and 29 patients in CMI had scored above the respective cut-off levels to indicate significant emotional distress.

\begin{tabular}{|c|c|c|c|c|}
\hline \multirow{2}{*}{ Variables } & \multirow{2}{*}{ GHQ } & \multicolumn{2}{|c|}{ HADS } & \multirow{2}{*}{ CMI } \\
\hline & & Anxiety & Depression & \\
\hline Age & -0.14 & 0.13 & 0.09 & 0.08 \\
\hline Education & -0.14 & -0.14 & -0.21 & -0.05 \\
\hline Income & -0.01 & -0.19 & -0.03 & -0.05 \\
\hline $\begin{array}{l}\text { Socio- } \\
\text { economic } \\
\text { status }\end{array}$ & -0.12 & -0.04 & -0.13 & -0.20 \\
\hline $\begin{array}{c}\text { Time since } \\
\text { diagnosis }\end{array}$ & -0.03 & -0.09 & 0.19 & 0.10 \\
\hline $\begin{array}{c}\text { Time since } \\
\text { ART }\end{array}$ & 0.07 & 0.08 & $0.32 *$ & $0.41 *$ \\
\hline CD4 Count & 0.16 & 0.09 & -0.02 & 0.21 \\
\hline CD3 Count & -0.05 & -0.09 & -0.02 & 0.12 \\
\hline
\end{tabular}

Table 2. Correlations between Personal and Clinical variables and Psychological Morbidity

$\mathrm{N}=60 ; \mathrm{df}=58$; Values refer to Pearson's ' $\gamma$ '.

CD4 and CD3 counts were not done in 7 patients and in these two rows, $\mathrm{df}=51$.

$* \mathrm{p}<0.05$.

Relevance of personal and clinical variables to the pattern of screening was made out by Pearson's correlation (Table 2). Results indicated that age, education, income, socioeconomic status, time since the diagnosis was made, CD3 count and CD4 count were not correlated significantly to scores in the screening tools. Duration after the start of ART was significantly correlated to HADS Depression and CMI scores.

Inter-correlations between the scores in three devices showed that scores in GHQ were not significantly correlated to HADS Anxiety, HADS Depression, or CMI scores whereas the latter three evinced statistically significant correlations among themselves (Table 3).

\begin{tabular}{|c|c|c|c|}
\hline \multirow{2}{*}{ GHQ } & \multicolumn{2}{|c|}{ HADS } & \multirow{2}{*}{ CMI } \\
\cline { 2 - 3 } & Anxiety & Depression & 0.07 \\
\hline GHQ & 0.01 & 0.02 & $0.71^{*}$ \\
\hline HADS Anxiety & & $0.65^{*}$ & $0.54^{*}$ \\
\hline HADS Depression & & & \\
\hline \multicolumn{2}{|c|}{ CMI } & & \\
\hline \multicolumn{2}{|c|}{ Table 3. Inter-correlations between Scores } \\
in the Screening Instruments \\
\hline
\end{tabular}

$\mathrm{N}=60 ; \mathrm{df}=58$; Values refer to Pearson's ' $\gamma$ '.

$* \mathbf{p}<.01$.

\begin{tabular}{|c|c|c|c|c|c|}
\hline \multirow{2}{*}{$\begin{array}{l}\text { Screening } \\
\text { Methods }\end{array}$} & \multicolumn{2}{|c|}{$\begin{array}{c}\text { Clinical Diagnosis } \\
\text { of Morbidity }\end{array}$} & \multirow{2}{*}{$\begin{array}{c}\text { True } \\
\text { Positive } \\
\text { Rate }\end{array}$} & \multirow{2}{*}{$\begin{array}{c}\text { True } \\
\text { Negative } \\
\text { Rate }\end{array}$} & \multirow{2}{*}{$\chi^{2}$} \\
\hline & $\begin{array}{l}\text { Present } \\
(n=38)\end{array}$ & $\begin{array}{l}\text { Absent } \\
(n=22)\end{array}$ & & & \\
\hline GHQ: & & & & & \\
\hline 7 or more & 38 & 22 & & & \\
\hline 6 or less & 00 & 00 & 100 & 0 & \\
\hline $\begin{array}{c}\text { HADS } \\
\text { Anxiety: }\end{array}$ & & & & & \\
\hline 7 or more & 17 & 01 & & & \\
\hline 6 or less & 21 & 21 & 44.74 & 95.45 & 10.72* \\
\hline $\begin{array}{c}\text { HADS } \\
\text { Depression: }\end{array}$ & & & & & \\
\hline 8 or more & 26 & 02 & & & \\
\hline 7 or less & 12 & 20 & 68.42 & 90.91 & $19.71 * *$ \\
\hline $\begin{array}{c}\text { CMI: } \\
10 \text { or more }\end{array}$ & 24 & 05 & & & \\
\hline 9 or less & 14 & 17 & 63.16 & 77.27 & $9.12 *$ \\
\hline
\end{tabular}

Table 4. Statistical Association between Screening Methods and Clinical diagnosis

$\mathrm{df}=1$.

${ }^{*} \mathbf{p}<.01 ; * * \mathbf{p}<.001$.

Comparison between clinical methods and screening devices was done using Chi-square test (Table 4). GHQ identified all patients as positive, disturbed, implying that false positive identification was very high. HADS Anxiety scores indicated that though most of the negatively identified individuals were not evincing clinically identifiable psychopathology, more than half of clinically disturbed patients were found to score below the cut-off levels in the screening. Thus, true negative rates were high indicating a good specificity; and true positive rate was low underlying a lack of sensitivity. HADS Depression scores showed similar results and false negative scores were less compared to CMI. Twenty six clinically disturbed patients had scored above the cut-off levels indicating a comparably better sensitivity among the tests. In CMI, five patients had falsely scored above the cut-off and 14 out of 38 clinically positive patients were missed because of below-the-cut-off scores.

\section{DISCUSSION}

Results of the study reiterated the high prevalence of psychological morbidity among patients with HIV disease. On being screened with various tools, all of them showed that the extent of psychological morbidity was higher than in the general population. A prevalence rate of anxiety of 6 to 14 percent and of depression of 20 percent had been described for the general population.[3],[10] Clinical assessment showed that more than three fifths of the patients suffered from psychological morbidity though results from HADS and CMI were much less. GHQ scores identified all patients as suffering from significant psychological disturbances.

Correlations with personal variables and psychological morbidity showed that none of the variables were significantly related. Though education, income and socioeconomic status were inversely related to morbidity indicating a positive protective effect, the association was not statistically significant. Among the clinical variables, duration after the start of ART was positively correlated to all the scores and significantly so to HADS Depression and CMI, indicating the demoralising consequences of long-term treatment. Need for long-term treatment always signified for 
the individual either a severe illness or an adverse course.[1] Laboratory markers of the illness were not significantly related to psychological disturbances at all, indicating patients' unawareness of their predictive value in prognostication.

Inter-correlations between raw scores of the instruments revealed the significance of statistical association in measuring a common attribute. GHQ was not significantly correlated to any other measure. Inter-correlations between HADS Anxiety and Depression scores were significant and both were significantly correlated to CMI scores. Squaring ' $r$ ' between HADS Anxiety and HADS Depression with CMI indicated that $50 \%$ and $71 \%$ of the variance was shared between them respectively. Though prevalently used, CMI has been criticised for its difficulty in differentiating between traits and symptoms, its loading with hypochondriacal items and the possibility of positional responses.[4] Extent of variability in the instruments indicated that each device was sensitive to varied aspects of morbidity. With lowest number of false-positive and false-negative responses, HADS Depression score appeared to be a more suitable measure to identify the emotionally disturbed patients.

Measuring their utility against the benchmark of clinical evaluation, the results indicated that GHQ failed as a practical tool for screening. GHQ was over-inclusive in identifying as sick all the patients and lacked specificity. HADS subscales and CMI were found to be less over-inclusive, but missed out many disturbed individuals, indicating their lack of desired sensitivity.

\section{CONCLUSION}

Results of the study reveal that there is a considerable occurrence of psychological morbidity among HIV victims and that most personal and clinical parameters were not significantly related to scores in screening instruments. Robinson observed that physical illnesses did not dramatically alter the presentation or applicability of standard diagnostic criteria of mental illness. Rating scales should be used with caution and recognition that they are not a substitute for specifically eliciting the symptoms associated with each mental illness. Judged against clinical evaluation, all the instruments did not meet the anticipated levels of sensitivity and specificity. GHQ failed as a dependable instrument for screening, and HADS Depression scores appeared to be the best choice among the three. Sensitivity and specificity should not be viewed as invariant functions of the instrument itself. The cut-off point used to distinguish cases from non-cases and the influence of disease-prevalence are also related to the utility of the instrument.[9] The need to validate a more sensitive and specific instrument to screen HIV patients, particularly with disease-specific features is acutely felt.

\section{REFERENCES}

[1] Cohen F. Stress and bodily illness. Psychiatric clinics of North America 1981;4(2):269-86.

[2] Wilson JM, Jungner YG. Principles and practice of mass screening for disease. Bol Oficina Sanit Panam 1968;65(4):281-393.

[3] Tiemens BG, Ormel J, Simon GE. Occurrence, recognition, and outcome of psychological disorders in primary care. The American Journal of Psychiatry 1996;153(5):636-44.

[4] Goldberg DP. The detection of psychiatric illness by questionnaire: a technique for the identification and assessment of non-psychotic psychiatric illness. London, New York, Oxford University Press 1972.

[5] Zigmond AS, Snaith RP. The hospital anxiety and depression scale. Acta psychiatrica scandinavica 1983;67(6):361-70.

[6] Sharma M, Sethi BB, Bhiman A. Family jointness, social interaction and neuroses: a rural urban comparison. Indian journal of psychiatry 1984;26(4):357-63.

[7] Sabhesan S, Athiappan S. Families of head injured patients: their attitudes, experienced burden and psychopathology. Report submitted to Indian Council of Medical Research, New Delhi 1989.

[8] World Health Organization. International conference for the tenth revision of the international classification of diseases, Geneva1989.

[9] Zimmerman M, Mattia JI. Psychiatric diagnosis in clinical practice: is comorbidity being missed? Comprehensive psychiatry 1999;40(3):182-91.

[10] Strain JJ, Liebowitz MR, Klein DF. Anxiety and panic attacks in the medically ill. The Psychiatric clinics of North America1981;4(2):333-50. 